\title{
Evaluación y criterios de rehabilitación de la estructura de concreto reforzado de una refinería en un medio marino-costero
}

\author{
V. Millano ${ }^{1}$, O. Troconis de Rincón ${ }^{1}$, M. Sánchez ${ }^{1}$, M. Fernández ${ }^{1}$, R. Fernández ${ }^{1}$, W. Campos ${ }^{1}$, S. Delgado ${ }^{1}, J$ Guanipa ${ }^{1}$ y J. \\ Delgado ${ }^{1}$
}

${ }^{1}$ Centro de Estudios de Corrosión. Facultad de Ingeniería. Universidad del Zulia., Ciudad Universitaria, Maracaibo, Venezuela.

\begin{abstract}
Información del artículo DOI:

http://dx.doi.org/10.21041/ra.v

$\underline{1 i 2.9}$

Artículo recibido el 13 de

Noviembre de 2010, revisado

bajo las políticas de

publicación de la Revista

ALCONPAT y aceptado el 02

de Febrero de 2011. Cualquier

discusión, incluyendo la

réplica de los autores se

publicará en el primer número

del año 2012 siempre y cuando

la información se reciba antes

del cierre del tercer número

del 2011
\end{abstract}

(C) 2011 Alconpat Internacional

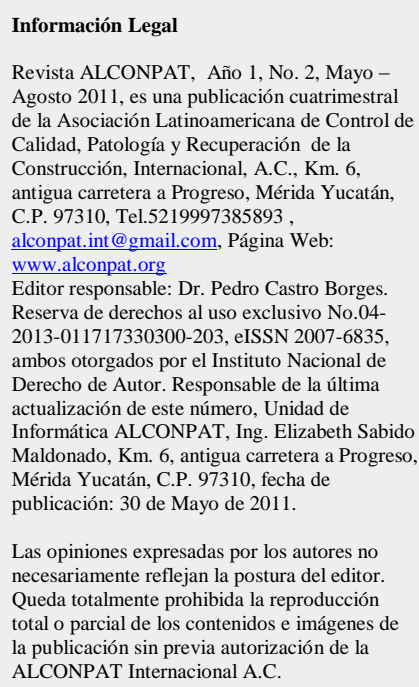

\section{RESUMEN}

En este trabajo se presenta la evaluación y el diagnóstico de los daños por corrosión y estructurales de la edificación de una Refinería construida en 1946, ubicada en un ambiente marino-costero. También se incluyen los criterios generales para su rehabilitación. Esta estructura consta de tres niveles, constituida por: vigas y columnas de acero estructural tipo doble $\mathrm{T}$ recubiertas con concreto antifuego, vigas y losas reforzadas, entre otros elementos. En sus instalaciones se encuentran una serie de equipos rotativos y de transferencia de calor que operan con agua de mar. Se realizaron pruebas fisicoquímicas y electroquímicas, que permitieron caracterizar el concreto y diagnosticar los daños por corrosión y estructurales. Esta evaluación permitió determinar que la causa principal del fenómeno corrosivo fue el elevado contenido de iones cloruro en el concreto, facilitado por el inadecuado diseño de los drenajes que ocasionaban el continuo mojado de los elementos estructurales y equipos en todos los niveles.

Palabras clave: corrosión; concreto armado; cloruros; inspección; rehabilitación; refinería.

\section{ABSTRACT}

This work presents the evaluation and diagnosis of the structural and corrosion damages in the facilities of a refinery built in 1946 in a marine coastal environment; it also includes the general criteria for its rehabilitation. The building comprises three levels and is constituted by beams and columns type double $\mathrm{T}$, which are made of structural steel and are coated with fire protectant concrete; other elements included reinforced beams and slabs, among others. The facilities have a series of heat transfer equipment that operate with sea water. A series of physicochemical and electrochemical tests allowed the characterization of the concrete and the diagnosis of referred damage. It was concluded that the main cause for the corrosion phenomena was the elevated content of chlorine in the concrete, which was promoted by the inadequate drainage design, which fostered the continuous wetting of the structural elements and equipment in all of the levels.

Key words: corrosión; reinforced concrete; chlorides; inspection; rehabilitation; refinery.

Autor de contacto: Oladis Troconis de Roncón (oladis1@yahoo.com) 
Revista ALCONPAT, Volumen 1, Número 2, Mayo - Agosto 2011, Páginas 99 - 114

\section{INTRODUCCIÓN}

La refinería posee en sus instalaciones una serie de equipos rotatorios y de transferencia de calor, tales como intercambiadores de calor y bombas, entre otros. Los intercambiadores de calor trabajan en su lado carcasa con agua del mar Caribe, y en su lado tubo con fluidos de proceso. Todos estos equipos se encuentran distribuidos en una edificación de tres niveles (Figura 1), conformada por columnas, vigas, soportes, losas, sin paredes perimetrales. La edificación está construida con columnas y vigas de acero estructural tipo doble $\mathrm{T}$ y con recubrimiento de concreto a prueba de fuego ("Fire Proof"). Algunas vigas, además de tener el perfil de acero están recubiertas con concreto reforzado con barras, perimetralmente, para incrementar su resistencia mecánica. La losa de techo del primer nivel es de concreto armado.

Ésta obra fue construida en 1946 y aún está en servicio. En ella se han venido realizando varias reparaciones inadecuadas en columnas, vigas y losa, las cuales no controlaron el proceso de corrosión del acero, y en algunos casos lo han potenciado; pudiendo esto, eventualmente, inducir a riesgos estructurales en dicha edificación. Estos elementos han estado expuestos a la contaminación de forma permanente, ya que se encuentran ubicados a orillas del mar Caribe y a un mojado continuo por fluidos del proceso.

La estructura a simple vista muestra una elevada cantidad de daños por corrosión, algunos de ellos con un grado muy avanzado de deterioro, los cuales se evaluaron para conocer el riesgo en cuanto a la estabilidad estructural de la misma. Así, el presente trabajo tiene por finalidad describir la inspección y discutir el diagnóstico de daños por corrosión y estructurales de dicha edificación, generando los respectivos protocolos de reparación/rehabilitación.

\section{PROCEDIMIENTO DE EVALUACION}

El trabajo se desarrolló en dos etapas: La primera etapa, denominada Inspección Preliminar y una segunda etapa, denominada Inspección Detallada, en la que se realizó el levantamiento fotográfico y de daños de todos los elementos estructurales.

El levantamiento de daños se efectuó mediante la inspección visual y el uso del martillo para determinar las áreas fofas. Luego, con el uso del Pacómetro se detectó la posición del acero (armado del concreto de revestimiento de los perfiles de acero doble $\mathrm{T}$ en vigas y columnas, $\mathrm{y}$ armadura de losa y soportes de equipo), en las áreas donde se realizarían las medidas electroquímicas (medición de potenciales y velocidad de corrosión).

V. Millano, O. Troconis de Rincón, M. Sánchez, M. Fernández, R. Fernández, W. Campos... 100 


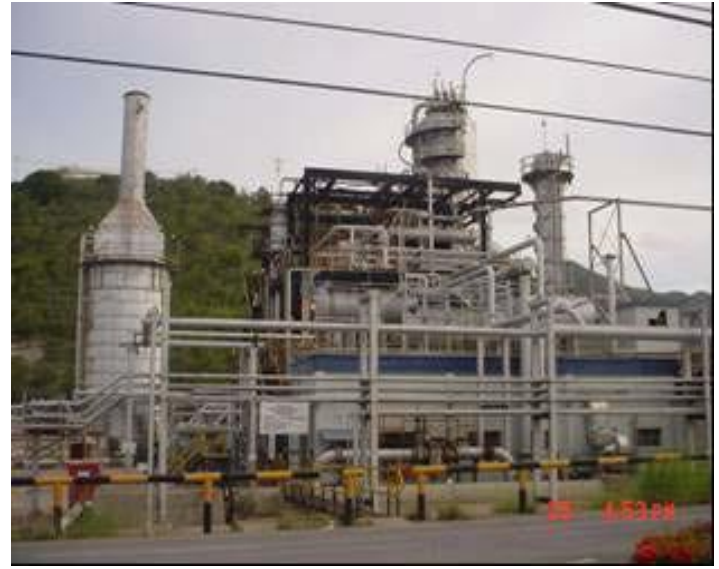

(a)

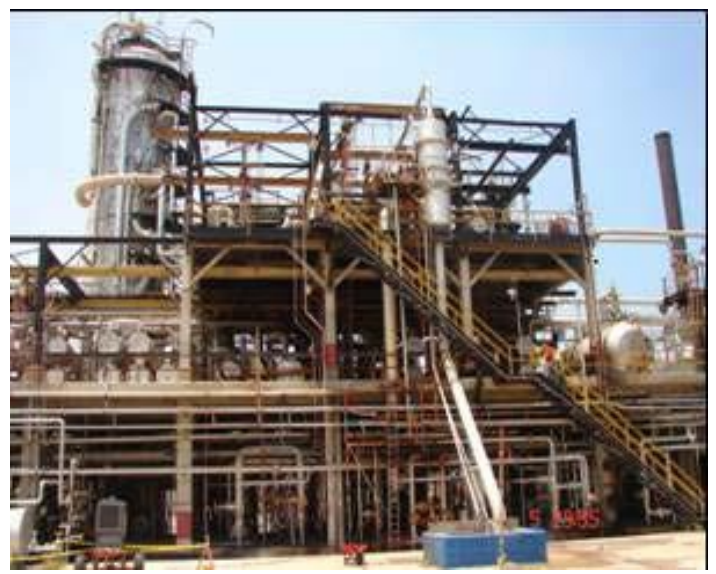

(c)

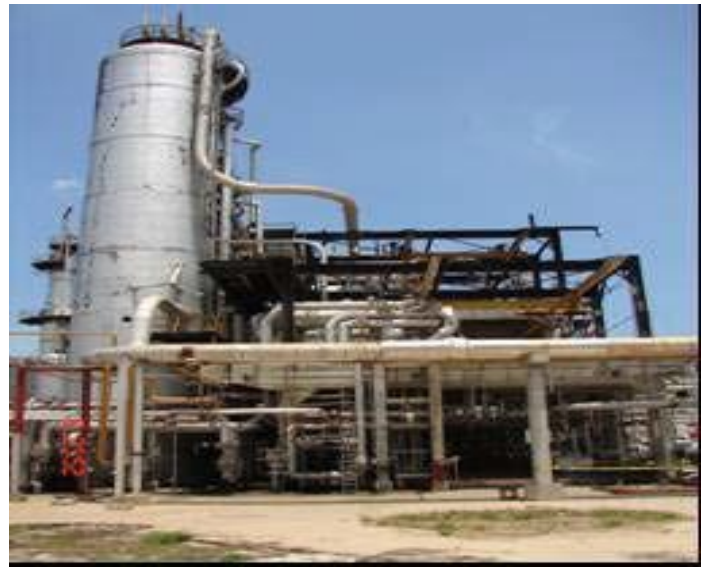

(b)

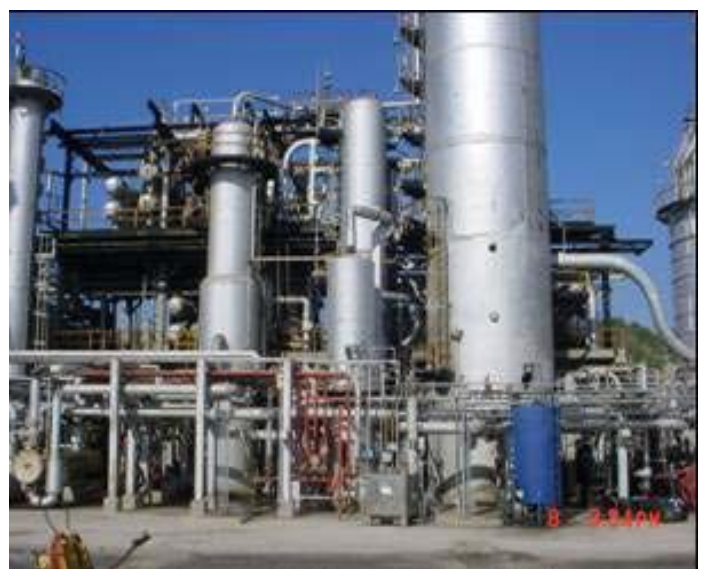

(d)

Figura 1. Vista General de la Refinería. (a) Cara Norte, (b) Cara Sur, (c) Cara Este, (d) Cara Oeste

La medición de potenciales se realizó según la norma ASTM C-876-87 (1987) y lo establecido en DURAR (Troconis et al, 1997), para identificar las áreas donde potencialmente el acero se esté corroyendo. Posteriormente, de acuerdo a los valores obtenidos, se determinaron las zonas donde se mediría la velocidad de corrosión, a través de Polarización Lineal utilizando un equipo de campo GECORR 6 (Feliú et al, 1993); el cual requiere de un mayor tiempo para la estabilidad de los parámetros electroquímicos involucrados. Estas medidas permiten definir claramente los sitios probables de corrosión activa en la estructura. Sin embargo, la medida de velocidad de corrosión se vio afectada por la densidad de acero en los elementos evaluados y por el elevado espesor de concreto, en algunos de ellos, lo cual no permitió confinar la corriente en todos los sitios seleccionados.

Estos resultados permitieron seleccionar los sitios para la extracción de los testigos y la evaluación fisicoquímica del concreto, para lo cual se extrajeron diez núcleos, distribuidos en el primer y segundo nivel de la edificación: dos de ellos ubicados en las columnas del primer nivel (N5 y N8), cuatro tomados en vigas ( $\mathrm{N} 4$ en primer nivel y N1, N2 y N3 en segundo nivel) y los cuatro núcleos restantes en diferentes sitios de la losa (N6, N7, N9 y N11), tomando como referencia las zonas con y sin daños aparentes. La Figura 2 muestra la planta del nivel 1 con la 
Revista ALCONPAT, Volumen 1, Número 2, Mayo - Agosto 2011, Páginas 99 - 114

ubicación e identificación de Columnas, Vigas y Soportes, y los sitios de extracción de testigos en el primer nivel.

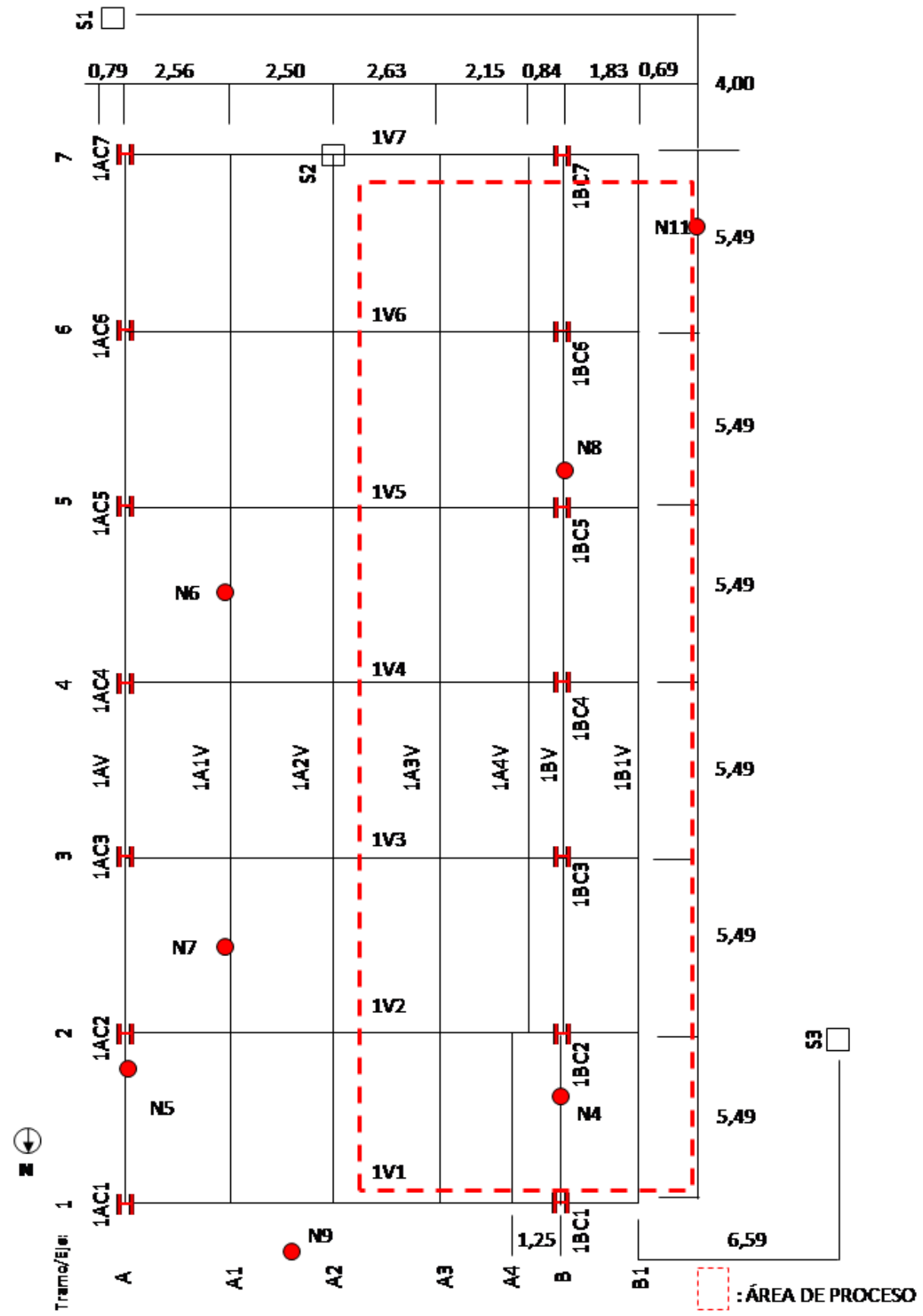

Figura 2. Planta del Nivel 1. Ubicación de Columnas, Vigas y Soportes, y sitios de extracción de testigos: N6, N7, N9 y N11, núcleos extraídos de la losa; N4, núcleo extraído en una viga del primer nivel; N5 y N8, núcleos extraídos en columnas. 
Revista ALCONPAT, Volumen 1, Número 2, Mayo - Agosto 2011, Páginas 99 - 114

\section{RESULTADOS Y DISCUSIÓN}

\section{Levantamiento de Daños.}

Se efectuó el levantamiento fotográfico y de daños de la condición actual de los elementos que conforman los tres niveles del edificio de la planta (Losa, Columnas y Vigas).

Primer y segundo nivel. En todos los niveles del edificio las columnas se encuentran distribuidas en dos ejes, A y B. En el primer nivel estas fueron identificadas desde la 1AC1 a 1AC7 para el eje A y desde 1BC1 a 1BC7 para el eje B (Figura 2). En ambos ejes se apreciaron columnas con daños de leves a moderados: grietas, áreas fofas, delaminación del concreto con acero expuesto (Figura 3), entre otros. En esta evaluación las columnas del eje A mostraron un mayor deterioro en la cara Este, por ser la que se encuentra expuesta a la intemperie y en dirección de los vientos preferenciales. Estos daños se han ido incrementando significativamente en el tiempo como se observa en la Figura 4, la cual muestra el estado de la cara Este de la columna 1AC2 en la primera inspección efectuada en el 2002 (Sánchez et al, 2007) y en esta última. Sin embargo, es en el eje B (Figura 3), donde las columnas presentaron los mayores daños, dado que en esta zona se encuentran localizados los equipos donde se maneja agua de mar como fluido de enfriamiento. Se determinó que un $45 \%$ de estos elementos requieren de una total sustitución del recubrimiento de concreto existente, ya que presentan grandes extensiones de áreas fofas, grietas de considerable espesor, así como delaminación del concreto con acero expuesto con corrosión de moderada a severa. Estos daños fueron potenciados por errados procedimientos de reparación localizada y por las condiciones ambientales y operacionales a las que se encuentra sometida la edificación. Al mismo tiempo se muestran indicios de incompatibilidad de los concretos en algunas columnas reparadas, ya que se observaron grietas a 45 grados vinculadas a los parches de reparación.

Es importante destacar que la mayoría de los daños se evidenció preferentemente en las zonas y caras con mayor exposición a los efluentes utilizados en el proceso (agua salobre con altas concentraciones de iones cloruros (> $30.000 \mathrm{ppm}$ ), debido a fugas en las tuberías, inadecuados diseños de canalización de efluentes y limpieza de equipos; situaciones éstas que se han incrementado en el tiempo. Estas irregularidades han generado delaminación del concreto, principalmente en aquellas zonas donde el cloruro ha alcanzado la concentración que inicia y desencadena los problemas de corrosión del acero en concreto (> $4000 \mathrm{ppm}$ ) (Troconis et al, 1997; DURACON, 2006; DURACON, 2007). 
Revista ALCONPAT, Volumen 1, Número 2, Mayo - Agosto 2011, Páginas 99 - 114

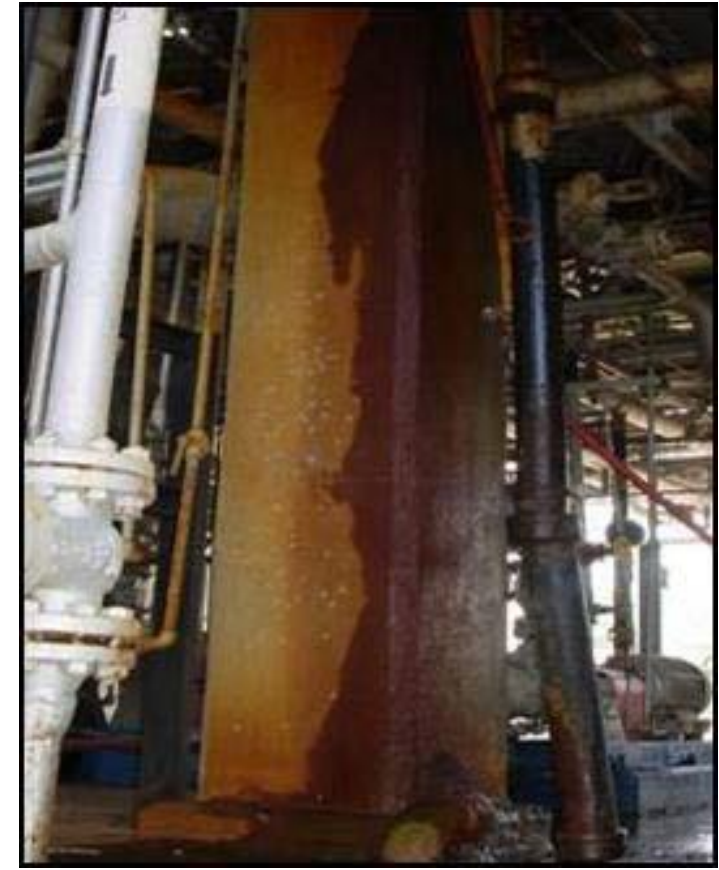

(a)

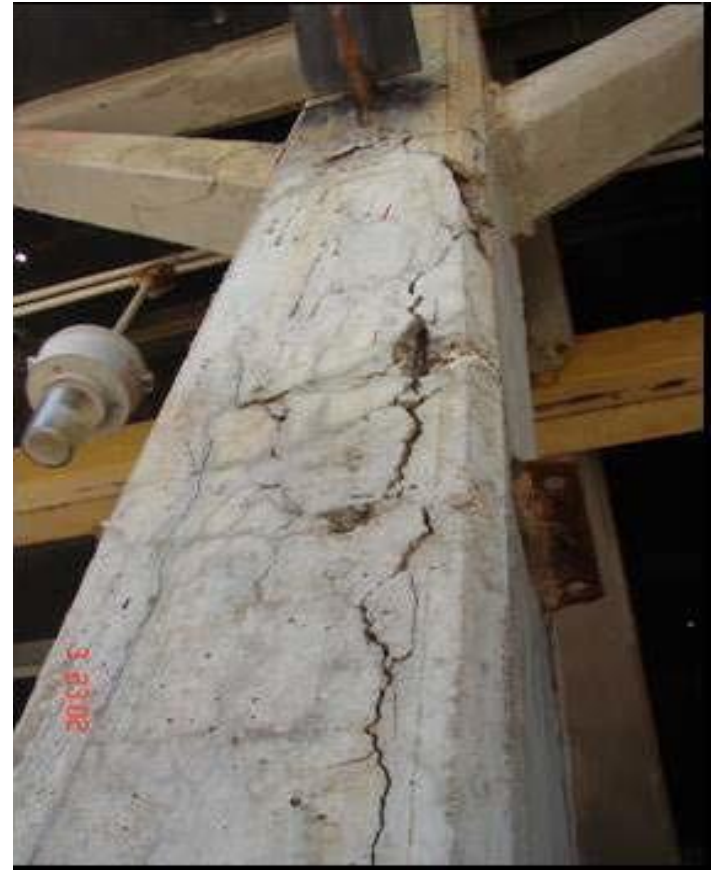

(b)

Figura 3. Levantamiento fotográfico de algunas columnas del eje B del primer y segundo nivel. (a) Cara Oeste y Sur con manchas de óxido, humedad y totalmente fofas. (b) Cara Norte de una columna del eje B del segundo nivel con grietas de gran espesor.

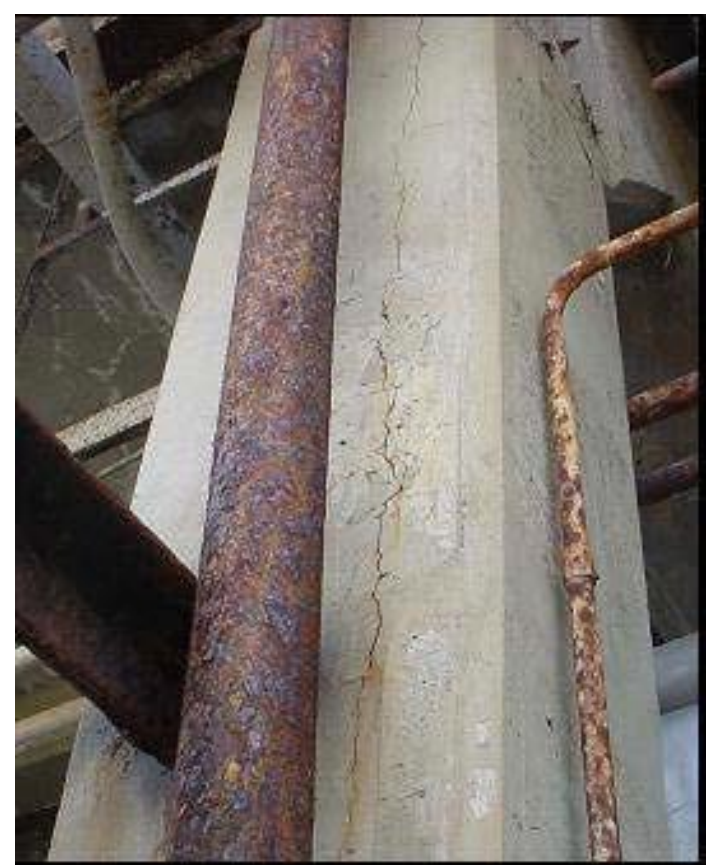

(a)

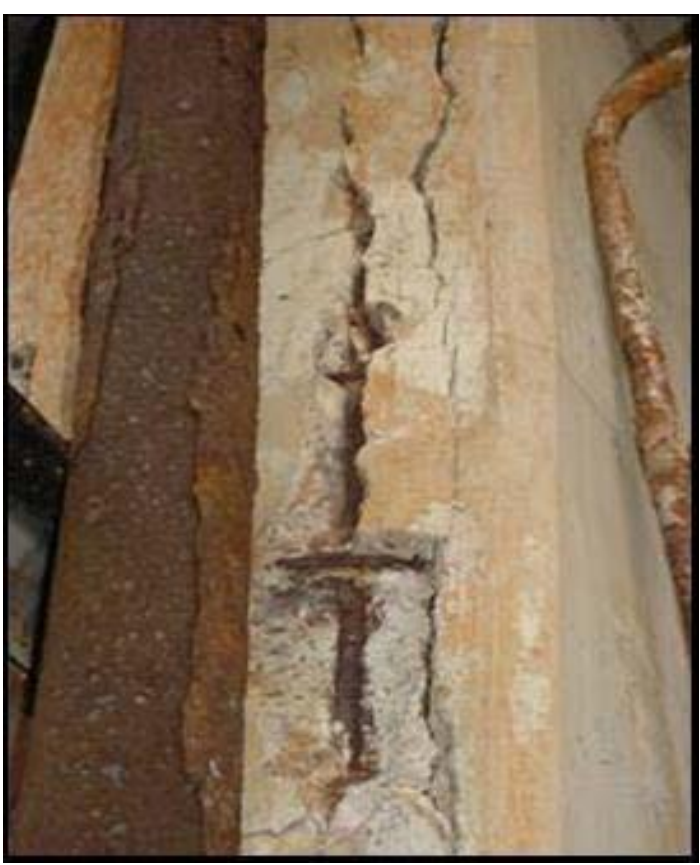

(b)

Figura 4. Levantamiento fotográfico de la Cara Este en la columna 1AC2. (a) Inspección 2002. (b) Inspección 2007, evidenciando el incremento de este daño con el tiempo de exposición. 
En relación a las vigas, estas se clasifican en principales y secundarias las cuales se encuentran dispuestas en dos sentidos: de Este a Oeste siete vigas principales de 13,99 m y de Norte a Sur siete vigas secundarias en seis tramos de aproximadamente $5,49 \mathrm{~m}$ cada uno (Figura 2), para el primer y segundo nivel. Del mismo modo que para las columnas, en las vigas principales la mayor cantidad de daños se observó en zonas cercanas a la línea de operación de los equipos, y áreas con problemas de fuga o inadecuados drenajes.

Del levantamiento fotográfico y de daños para las vigas principales, (Figura 5), se evidencia la necesidad de remover por completo el concreto de, al menos, dos vigas principales; ya que las zonas que recientemente fueron reparadas potenciaron la corrosión de las zonas adyacentes (Figura 6), presentando estas últimas áreas fofas, manchas de humedad, manchas de óxido, lixiviación, grietas de gran espesor y en algunos casos hasta delaminación del concreto con acero expuesto. El resto de las vigas principales mostró daños de leves a moderados, necesitando reparaciones parciales según el tipo de daño y extensión del mismo.

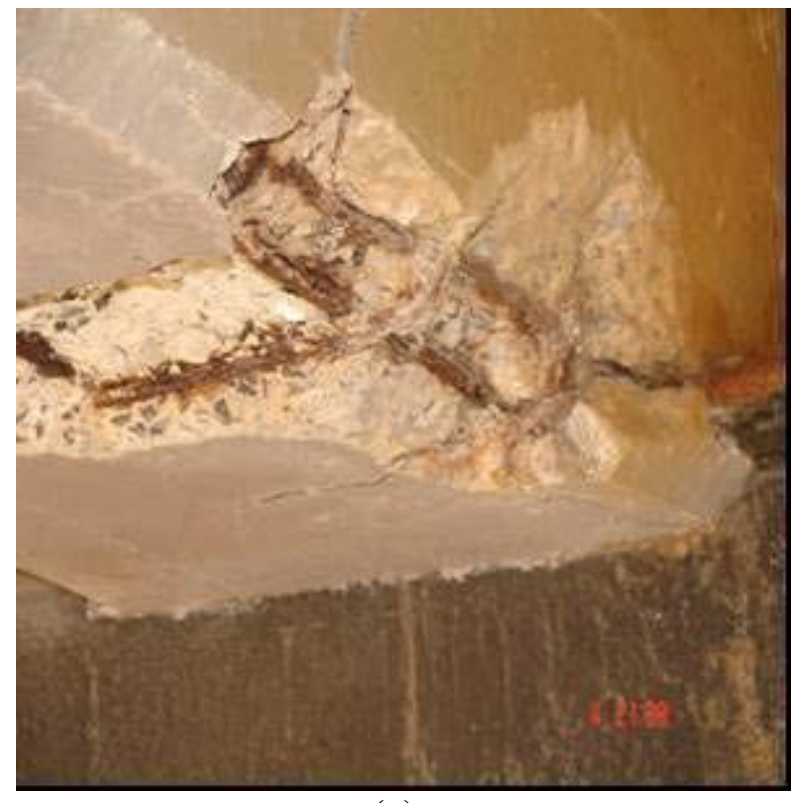

(a)

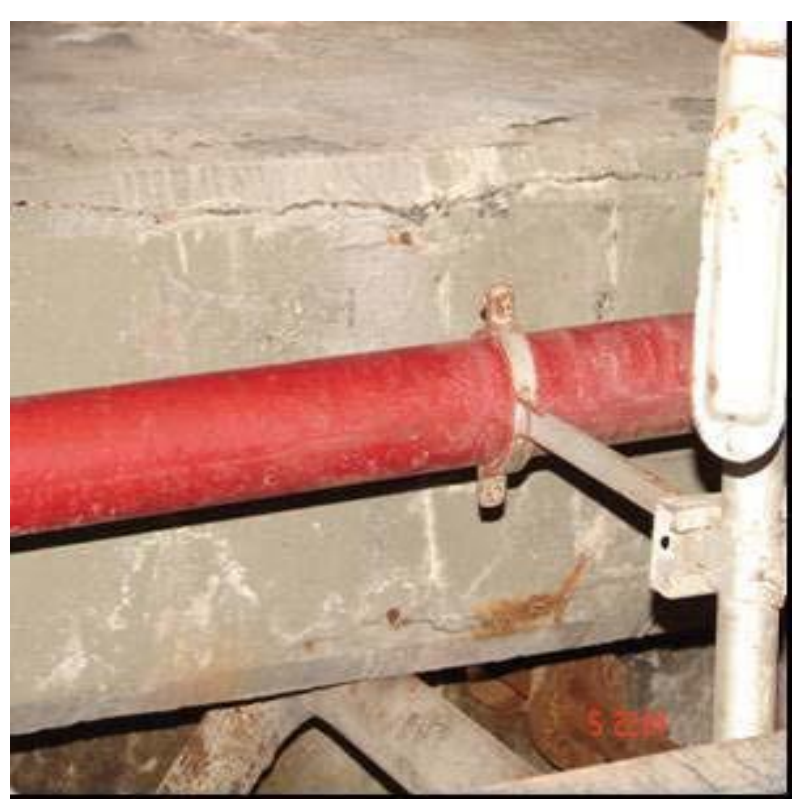

(b)

Figura 5. Levantamiento fotográfico de la Cara Sur de dos vigas principales con evidente daños por corrosión. a) Concreto delaminado y acero expuesto, b) Concreto agrietado y manchas por lixiviación

Es importante mencionar que las vigas secundarias, orientadas de norte a sur, presentan un deterioro generalizado mayor al mostrado por las vigas principales, con daños localizados significativos como se observa en la Figura 7. Esto amerita la total sustitución del concreto en todos estos elementos, lo cual ya se había indicado en la oportunidad de la primera inspección (Sánchez et al, 2007), pero no se realizó, sino que se ejecutaron reparaciones localizadas. Esto potenció la corrosión del acero en la zona no reparada, dada la formación de celdas galvánicas. 
Revista ALCONPAT, Volumen 1, Número 2, Mayo - Agosto 2011, Páginas 99 - 114

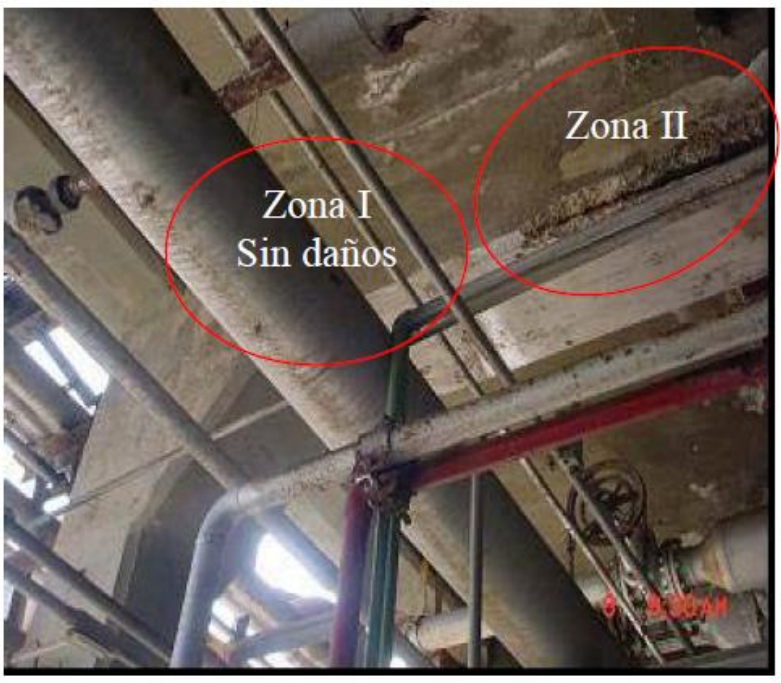

(a)

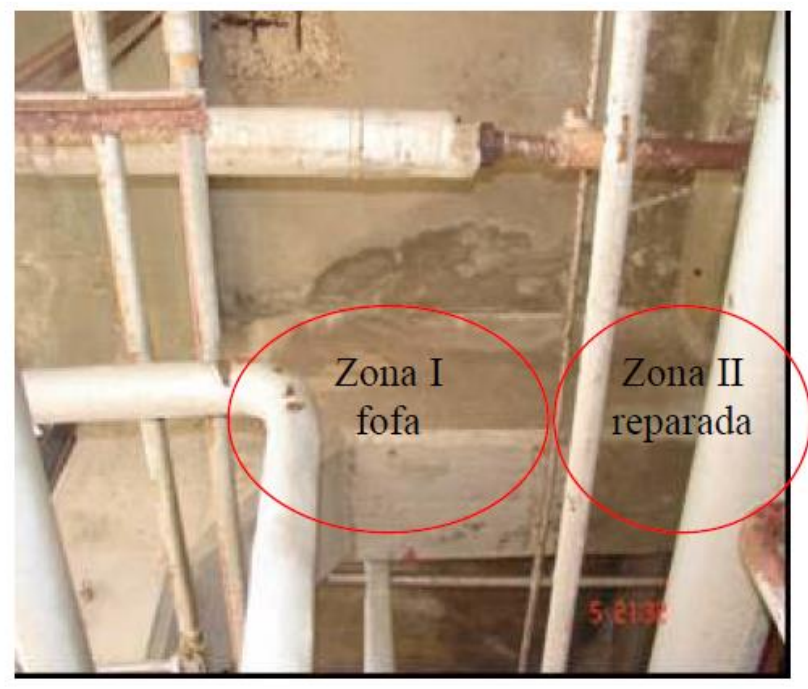

(b)

Figura 6. Levantamiento fotográfico de la Cara Norte-inferior de una viga principal del primer nivel durante ambas inspecciones a) Inspección 2002, con delaminación y acero expuesto b) Inspección 2007, donde se muestra la viga ya reparada pero con área fofa y fisuras por los errados procedimientos de reparación.

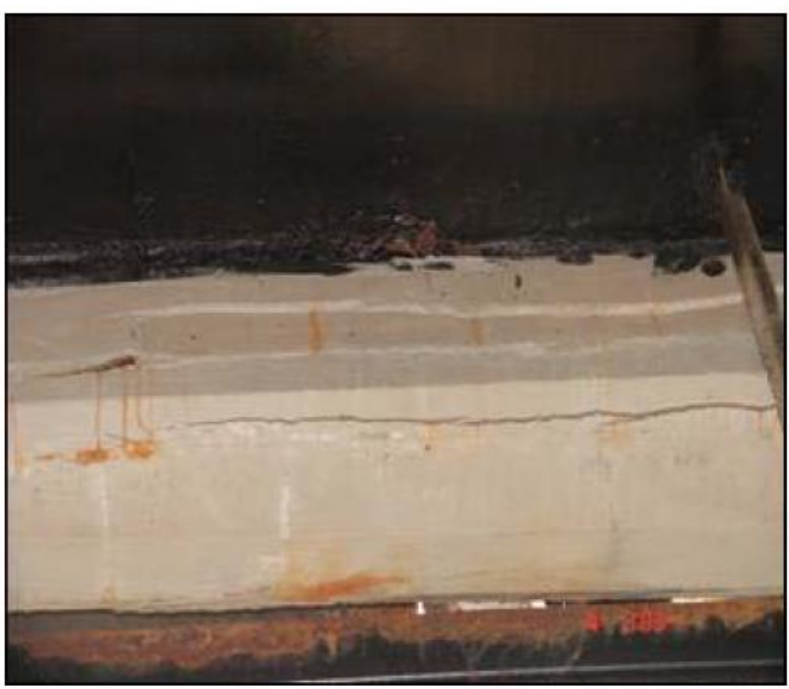

(a)

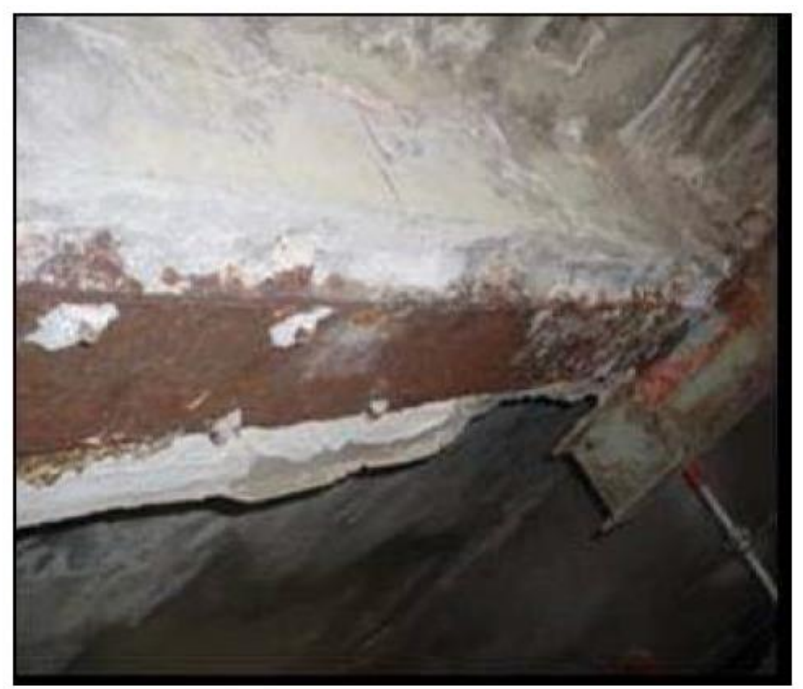

(b)

Figura 7. Levantamiento fotográfico de algunas vigas secundarias con los daños típicos encontrados. a) agrietamiento, b) delaminación con acero expuesto y concreto restante lixiviado y con depósitos de sal.

Con respecto a la losa, esta ha mostrado también un incremento importante en su deterioro, desde la primera inspección en el 2002; lo cual, eventualmente, puede comprometer la capacidad portante de la misma. La Figura 8 muestra los daños típicos encontrados en toda la extensión de la losa, representando un $70 \%$ de la misma; lo cual ameritó, por motivos de seguridad, la colocación de mallas de acero en su zona inferior y el apuntalamiento de algunas zonas. Esta situación ameritó una evaluación estructural que determinó la finalización de la vida residual de este elemento, comprometiéndola estructuralmente. De aquí que se conciba la sustitución completa de la losa que divide los dos primeros niveles. 


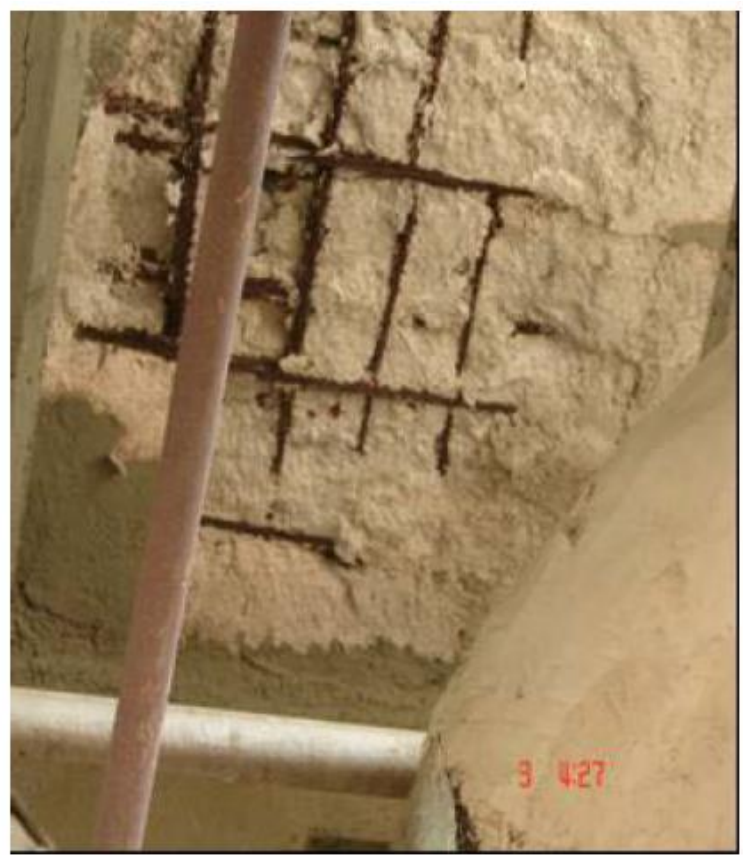

(a)

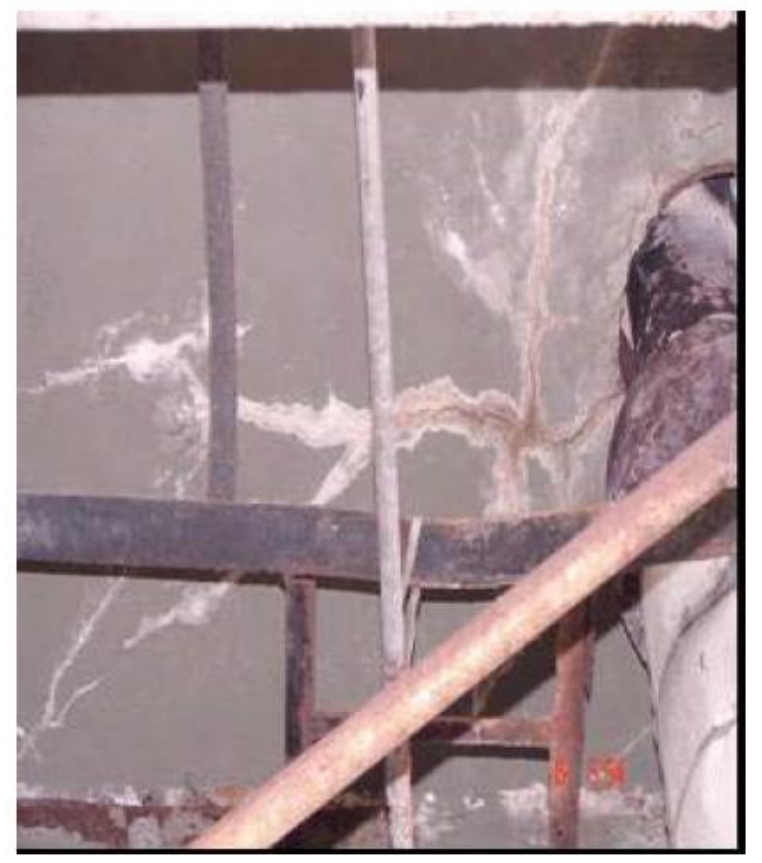

(b)

Figura 8. Levantamiento fotográfico de la losa a) Delaminación del concreto con acero expuesto, con corrosión severa. b) Agrietamiento de la losa con manchas por lixiviación y percolación del concreto.

Tercer Nivel. Este está construido con vigas y columnas doble T de acero sin recubrimiento de concreto antifuego, y láminas de acero como piso; debido a su ubicación y completa ventilación. La mayor parte de estas láminas de acero presentan un gran número de problemas por corrosión, debido a los errados procedimientos para los drenajes, mal diseño de los goteros y pendientes; facilitando así el estancamiento del agua, no solo del proceso sino de las lluvias, aunado a la falta de mantenimiento, motivo por el cual algunas zonas se han consumido completamente.

\section{Ensayos electroquímicos.}

La selección de los elementos para la evaluación electroquímica y fisicoquímica, está basada en la información obtenida durante el levantamiento de daños. Otros factores que se consideraron para su selección fueron: áreas de acumulación y contacto continuo con el agua de proceso en función a drenajes y elementos que faciliten estas condiciones. Es importante indicar que no fue posible efectuar medidas de velocidad de corrosión, dada la elevada densidad del armado de la losa, la presencia de perfiles doble $\mathrm{T}$ de acero en columnas y vigas en conjunto con el armado de las mismas.

En relación a la losa se seleccionaron áreas de las pocas zonas localizadas fuera del área de proceso, que no mostraban daños, determinándose potenciales promedios entre -150 y $-450 \mathrm{mV}$ vs $\mathrm{Cu} / \mathrm{CuSO} 4$, de acuerdo a su distancia del área de proceso. Esto demuestra que los daños por corrosión están vinculados al manejo del agua de mar en el área de proceso, como ya se ha indicado anteriormente.

En la Figura 9 se muestra uno de los resultados típicos para una de las vigas parcialmente reparada, donde la evaluación se efectuó sobre la zona reparada; alcanzándose potenciales de hasta $-329 \mathrm{mV}$ vs $\mathrm{Cu} / \mathrm{CuSO} 4$, lo que indica una alta potencialidad de corrosión del refuerzo (más negativo que $-250 \mathrm{mV}$ vs. $\mathrm{Cu} / \mathrm{CuSO} 4$ ), independiente de la cercanía a la zona no reparada. Esto sugiere que la reparación no fue de la calidad requerida para este ambiente de exposición. Adicionalmente, como se muestra en el levantamiento de daños (Figura 10), ya se presentan fisuras, tanto en zonas reparadas como en aquellas que no lo fueron.

Evaluación y criterios de rehabilitación de la estructura de concreto reforzado de una... 


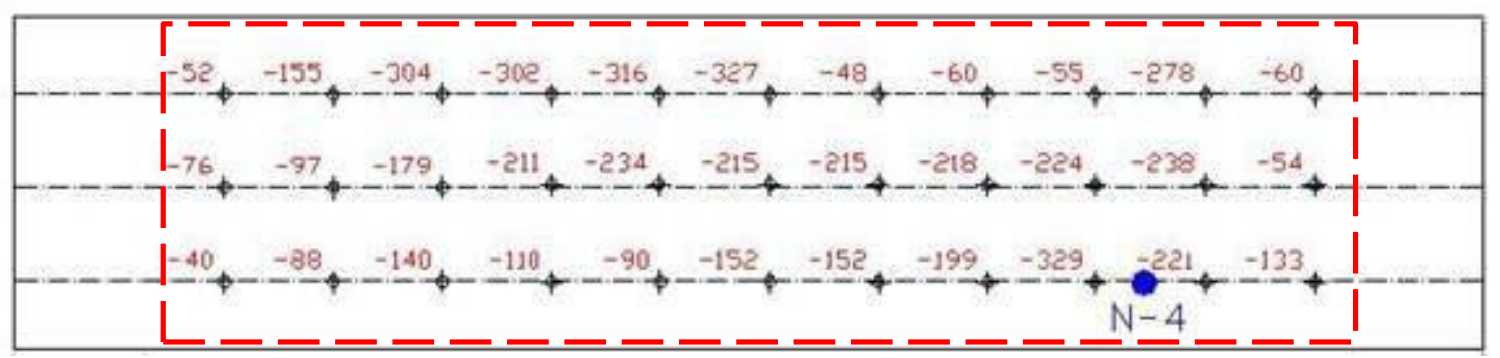

Figura 9. Potenciales de corrosión medidos en la zona reparada de una viga secundaria del primer nivel, parcialmente reparada, en la zona demarcada.

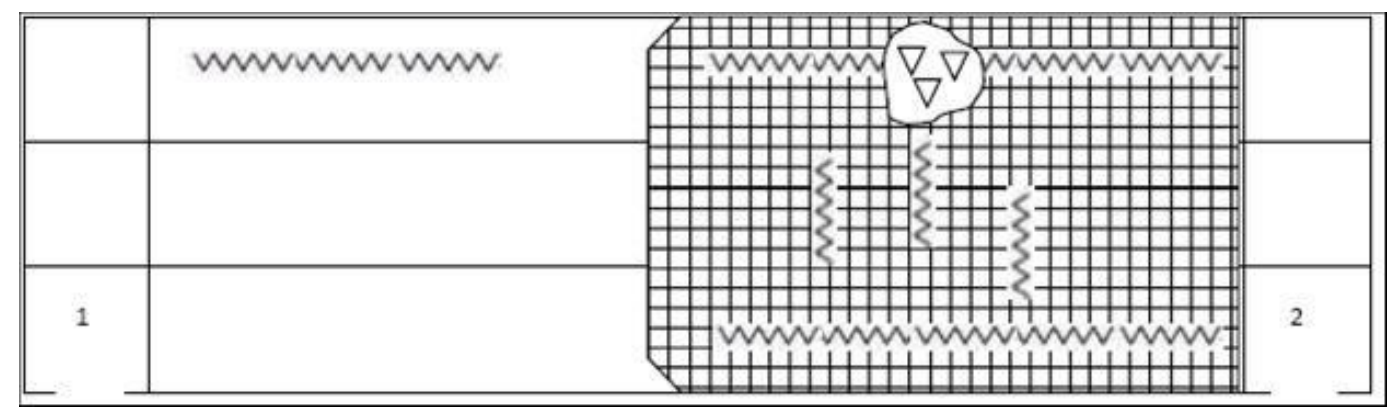

Figura 10. Levantamiento de daños de la viga secundaria parcialmente reparada ( indicada en la Figura 9, mostrando fisuras ( $\sim$ ) y área lixiviada $(\Delta)$

\section{Ensayos Fisicoquímicos.}

La Tabla 1 muestra, algunos de los resultados obtenidos en los diferentes elementos evaluados.

En esta se evidencia una falta de uniformidad en la calidad del concreto e incluso diferencias significativas de una zona de la losa a otra $(216$ a $303 \mathrm{~kg} / \mathrm{cm} 2)$, y en un mismo tipo de elemento (viga 2V3). Esta última situación llama mucho la atención, ya que se presentó para las áreas y elementos reparados parcialmente, caso de la viga 2V3, donde la resistencia a la compresión del concreto de reparación es $40 \%$ mayor al concreto original, pudiendo esto crear diferencias en el comportamiento físico entre los dos concretos frente a las solicitaciones mecánicas, facilitando la falla del concreto en la zona reparada, si esta no se ejecutó adecuadamente (ICRI, 1995). De igual forma se muestran los resultados del ensayo de porosidad, los cuales muestran un amplio rango de valores, en su mayoría correspondientes a una inadecuada calidad del concreto, con porosidades mayores al 15\%. Aun cuando los núcleos N7 y N11, correspondientes a la losa, indican una mejor calidad del concreto, ésta no es la adecuada para este ambiente tan agresivo de exposición, donde la porosidad del concreto debería ser inferior al 10\% (Troconis, 1997).

Tabla 1.- Resultados de los ensayos fisicoquímicos de porosidad y resistencia a la compresión

\begin{tabular}{|c|c|c|c|c|c|}
\hline Núcleo & Elemento & Ubicación & $\begin{array}{c}\text { XCO2 } \\
(\mathbf{m m})\end{array}$ & $\begin{array}{c}\text { Porosidad } \\
\mathbf{\%}\end{array}$ & $\begin{array}{c}\mathbf{f c k} \\
\left(\mathbf{k g} / \mathbf{c m}^{\mathbf{2}}\right)\end{array}$ \\
\hline N1 & Viga & Sur & 3 & 16 & - \\
N3 & Viga & Norte & 1 & 17,3 & - \\
N4 & Viga & Oeste & 0 & 20,3 & - \\
N6 & Losa & Este & 2,4 & 16,9 & 216 \\
N7 & Losa & Este & 0 & 11,6 & - \\
N9 & Losa & Nor-Este & 3 & 19,1 & 218 \\
N11 & Losa & Sur-Oeste & 2,1 & 10,9 & 303 \\
\hline
\end{tabular}

V. Millano, O. Troconis de Rincón, M. Sánchez, M. Fernández, R. Fernández, W. Campos... 108 
Por otra parte, los bajos espesores carbonatados detectados en todas las evaluaciones $(<12 \mathrm{~mm})$, indican que éste no es el mecanismo por el cual el acero se está corroyendo. Básicamente, todos los problemas de corrosión detectados se deben al ingreso de los iones cloruro al concreto.

Los resultados de perfiles de concentración de cloruros (Figura 11), muestran una considerable contaminación por este agresivo, particularmente para los núcleos N7 (zona de estancamiento de agua) y N11 (zona con estalactitas y depósitos de sal en su lado techo) de la losa, correspondientes a los sitios seleccionados como los de mayor riesgo por corrosión en base al levantamiento de daños; alcanzándose, en algunas zonas, valores equivalentes a la concentración del agua salobre que maneja el proceso $(>25.000 \mathrm{ppm})$. En todos los perfiles evaluados se muestran niveles superiores al límite de riesgo para corrosión del acero $(>4.000 \mathrm{ppm})$, a nivel de la armadura $(\approx 2 \mathrm{~cm})$, en correspondencia con los resultados electroquímicos y el levantamiento de daños

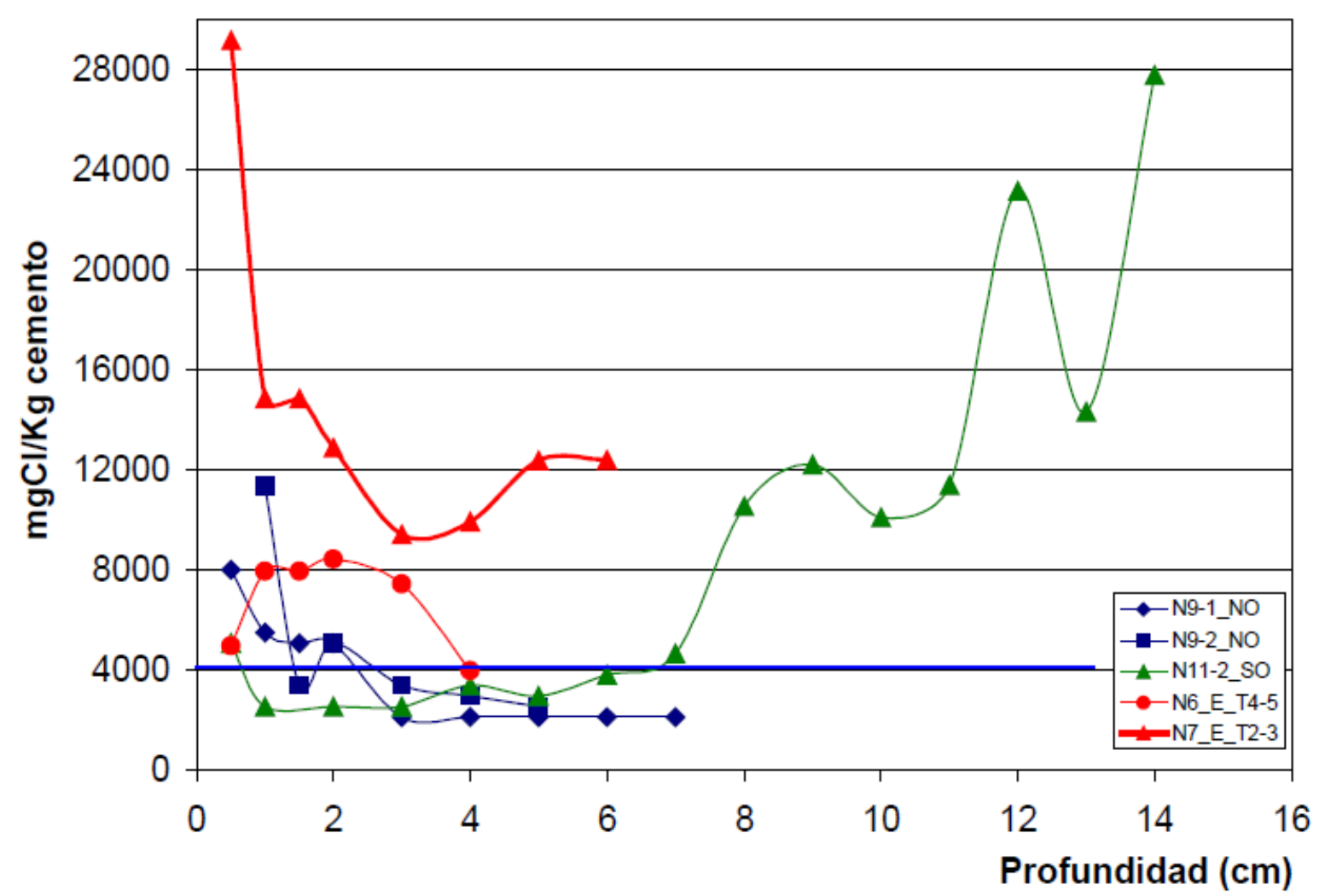

Figura 11. Perfil de concentración de iones cloruros solubles en muestra de concreto correspondiente a los testigos extraídos en la Losa, desde el nivel 2 (piso).

La Figura 12 muestra el contenido de iones cloruro encontrado en diferentes vigas. Para el caso del Núcleo N3, este se dividió en dos partes debido a que presentó una zona reparada (N3A) y otra no (N3B). En general las vigas muestran un alto contenido de cloruros, particularmente en las zonas no reparadas (N1); mientras que en el resto de los testigos (N2, N3A y N4), tomados en zonas reparadas, aún cuando el contenido de cloruros no es tan alto ya se encuentra en el orden de los $4.000 \mathrm{ppm}$ a profundidades de $4 \mathrm{~cm}$, a pocos años $(<4)$ de su reparación. Esto puede deberse no solo a la contaminación externa, sino a la difusión de iones cloruro desde las zonas no reparadas, lo cual se facilita por la alta humedad imperante en la zona (riego constante de agua y ambiente marino tropical).

Evaluación y criterios de rehabilitación de la estructura de concreto reforzado de una... 
Revista ALCONPAT, Volumen 1, Número 2, Mayo - Agosto 2011, Páginas 99 - 114

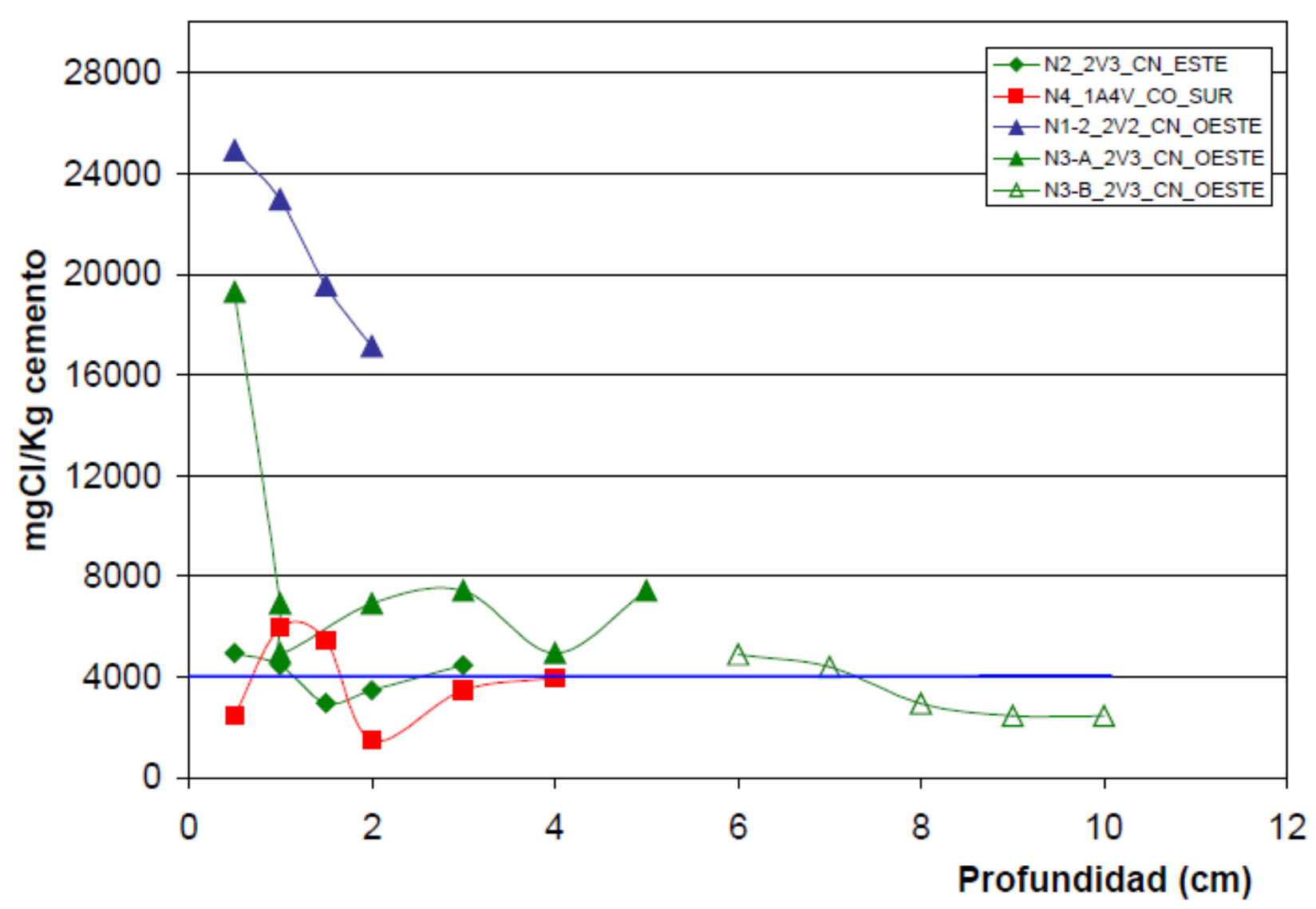

Figura 12. Perfil de concentración de iones cloruro solubles en muestra de concreto correspondiente a los testigos extraídos en Vigas

\section{CONCLUSIONES}

1. La corrosión del acero se debe, principalmente, al mojado continuo de los elementos y equipos, por el agua de mar usada como fluido de enfriamiento, la cual se dispersa en toda la extensión de los pisos superiores hasta los inferiores debido al inadecuado diseño de los desagües.

2. Los daños estructurales se deben a las grandes extensiones de áreas fofas, delaminadas y con acero expuesto que han disminuido la capacidad portante de elementos estructurales como losa y vigas, necesitando la sustitución parcial de vigas y total de la losa.

3. Los elementos próximos al eje B fueron los más afectados, ya que se encuentran en el área de los equipos que manejan agua de mar como fluido de enfriamiento.

4. Las reparaciones localizadas potenciaron los daños de las zonas vecinas debido a la formación de celdas galvánicas.

5. Los procedimientos de reparación utilizados no prestaron la protección adecuada, ya que al poco tiempo de intervenidas se presentaron fisuras y moderada actividad electroquímica.

6. La losa del primer nivel, reveló severos daños por corrosión que comprometen estructuralmente la misma y la seguridad del personal, requiriendo una inmediata intervención.

7. Se estableció el protocolo de reparación/rehabilitación, donde se indica el reemplazo total de la losa, debido al elevado grado de deterioro alcanzado para el presente estudio, la cual debe ser vaciada en sitio monolíticamente.

V. Millano, O. Troconis de Rincón, M. Sánchez, M. Fernández, R. Fernández, W. Campos... 110 
Revista ALCONPAT, Volumen 1, Número 2, Mayo - Agosto 2011, Páginas 99 - 114

\section{PROTOCOLO DE REPARACIÓN/REHABILITACIÓN}

La selección de los materiales de relleno (áridos), de recubrimiento y de acabado, debe realizarse bajo procedimientos de rigurosa calidad, ya que de ellos dependen sus funciones específicas correspondientes a dotar a la estructura metálica de resistencia al fuego en cuanto a aislamiento térmico se refiere. Propiedad ésta que pudiera evaluarse según lo dispuesto en las NORMAS COVENIN 621 (B) y ASTM. E-119 y mejorar la resistencia a la corrosión de los elementos metálicos. Para realizar la reparación/rehabilitación se recomienda utilizar un concreto con resistencia al fuego, seguido de un mortero resistente al medio ambiente, el cual además puede ser pintado (hidrofugante) para incrementar su resistencia a este ambiente tan agresivo de exposición.

Material para Protección Antifuego.

Con base a lo anteriormente expuesto, se presenta a continuación la información relacionada con el material de protección antifuego, el cual debe ser un concreto liviano no estructural utilizando parcialmente como agregado esferitas de arcilla expandida (tipo estructural): a1) Esferitas finas con granulometría entre 3,2 y $9,0 \mathrm{~mm}$ y a2) Esferitas medianas con granulometría entre 9,0 y $14,0 \mathrm{~mm}$.

La Tabla 2 muestra la dosificación correspondiente a un metro cúbico de concreto. Este diseño debe garantizar la durabilidad de la estructura bajo las condiciones de servicio.

Tabla 2. Cantidades de materiales para $1,0 \mathrm{~m}^{3}$ de concreto.

\begin{tabular}{|c|c|c|c|c|c|}
\hline $\begin{array}{c}\text { Agregado } \\
\mathbf{a 1}\left(\mathbf{m}^{\mathbf{3}}\right)\end{array}$ & $\begin{array}{c}\text { Agregado } \\
\mathbf{a 2}\left(\mathbf{m}^{\mathbf{3}}\right)\end{array}$ & $\begin{array}{c}\text { Arena } \\
\left(\mathbf{m}^{\mathbf{3}}\right)\end{array}$ & $\begin{array}{c}\text { Cemento } \\
(\mathbf{k g})\end{array}$ & $\begin{array}{c}\left.\text { Agua } \mathbf{( m}^{\mathbf{3}}\right) \\
\text { Prueba }\end{array}$ & $\begin{array}{c}\text { Agua }\left(\mathbf{m}^{\mathbf{3}}\right) \\
\text { Shotcrete** }\end{array}$ \\
\hline 0,30 & 0,30 & 0,60 & 297,5 & 0,190 & 0,114 \\
\hline
\end{tabular}

La cantidad de agua destacada con el símbolo (*) deberá respetarse para preparar la mezcla de prueba. Se espera que el ensayo de compresión arroje valores mayores a $400 \mathrm{~kg} / \mathrm{cm}^{2}$. La cantidad de agua destacada con el símbolo (**) se anota como recomendable para la mezcla que vaya a colocarse mediante concreto proyectado, pero la misma deberá ser ajustada mediante ensayos de campo.

Dado que esta mezcla tiene una buena resistencia al fuego ( $2 \mathrm{~h}$ aproximadamente, según norma ASTM 119), pero una baja durabilidad a este ambiente, se recomienda el uso de un inhibidor de corrosión en base a Nitrito de Calcio. El inhibidor comercial tiene aproximadamente un 30\% de nitrito de calcio, de tal manera que es necesario ajustar la mezcla para mantener la relación agua/cemento indicada. Las dosificaciones de inhibidor recomendadas son de 10 a $30 \mathrm{lt} / \mathrm{m} 3$. Dado que este concreto no es de la calidad exigida para este ambiente de exposición, se recomiendan $30 \mathrm{lt} / \mathrm{m} 3$ (la cantidad de agua agregada a la mezcla sería de 0,025 m3). Así, la cantidad de agua a agregar a la mezcla será de $0,089 \mathrm{~m} 3$ y la prueba se debe hacer con 0,165 m3.

Es importante señalar que se deben realizar pruebas preliminares de esta mezcla para garantizar la trabajabilidad requerida por el concreto proyectado.

Materiales para recubrimiento y acabado.

Para garantizar la geometría y confinamiento del material de relleno (Metal desplegado con peso de 1,36 a $1,62 \mathrm{~kg} / \mathrm{m}^{2}$ y nervios de $\left.3 / 8^{\prime \prime}(0,95 \mathrm{~cm})\right)$, se debe utilizar un material polimérico/plástico. Para el material resistente al ambiente con iones cloruro, debe considerarse una proporción de un volumen de cemento y tres volúmenes de arena normal para concreto con una relación $\mathrm{a} / \mathrm{c}=0,45$. Como sustituto de esta mezcla, preparada en obra, se puede colocar un material pre-empacado (morteros para proyección modificados con microsílice, de alta resistencia 
Revista ALCONPAT, Volumen 1, Número 2, Mayo - Agosto 2011, Páginas 99 - 114

mecánica temprana), el cual según la hoja técnica de algunos proveedores puede proyectarse a espesores de $1,2 \mathrm{~cm}$.

Para el acabado final pudiera utilizarse como primera opción un material con base cementosa que pueda aplicarse por rociado y cuya característica principal sea la de un recubrimiento "Waterproof", o un recubrimiento hidrofóbico para mayor durabilidad. Como segunda opción un "Mastic Intumescente" que tiene la propiedad de reaccionar cuando es expuesto al calor formando una estructura multicelular de mayor espesor.

\section{Métodos y procedimientos constructivos.}

Vigas y columnas. Para el caso de las vigas que tienen, además del perfil metálico, concreto armado perimetralmente, donde se requiere eliminar todo el concreto contaminado con cloruros y la sustitución de las barras con elevado deterioro, se propone inicialmente la demolición del concreto, preferiblemente con agua a presión. Esto implica reducir la capacidad de las vigas a la del perfil metálico original. Por ello, se modeló en el computador las vigas localizadas debajo de los intercambiadores (las más afectadas por la corrosión severa del armado), con la carga de los mismos, obteniendo como resultado que los perfiles originales de las vigas secundarias del nivel 1 , sin el concreto reforzado, solamente son capaces de resistir 2 intercambiadores en operación y 4 intercambiadores vacíos. Si esta condición no es posible, es necesario apuntalar la zona; pero esto dificultará la rehabilitación.

Una vez demolido el concreto, se debe reconstruir la sección original de la viga, con concreto proyectado, con dimensiones de 30x85 con 4 barras de 7/8"(o en su defecto de mayor diámetro) cercanas a la cara inferior con una distancia suficiente con estribos de diámetro 1/2"@20 cm, garantizando $5 \mathrm{~cm}$ de recubrimiento a la cara exterior de los estribos y un concreto con una relación a/c de 0,4 y un contenido de cemento de $400 \mathrm{~kg} / \mathrm{m} 3$ de concreto.

En relación a las vigas principales, en las cuales se apoyan las vigas antes referidas, deberán ser reparadas en los segmentos en los cuales el estudio de corrosión indique contaminación con cloruros, eliminando por completo el concreto contaminado y sustituyendo el acero deteriorado por barras sanas de las mismas dimensiones existentes, así como los estribos correspondientes, de acuerdo al procedimiento indicado anteriormente. Para esto se debe previamente apuntalar las vigas secundarias que soportan directamente los intercambiadores.

Para el caso de las vigas que no se encuentran reforzadas en su zona perimetral y de las columnas, el material para relleno puede ser colocado por el método de "Concreto proyectado". El procedimiento debiera ejecutarse en dos etapas.

En la primera etapa debe colocarse el material necesario para llenar parcialmente los "noyos" hasta una profundidad tal que los extremos de las alas del perfil de acero queden libres en una longitud no menor de $3 \mathrm{~cm}$. Finalizada esta primera etapa, se procederá a colocar el metal desplegado para definir la geometría del elemento estructural.

La segunda etapa se iniciará luego de colocado el metal desplegado y asegurada su posición. El material de relleno se colocará hasta garantizar un recubrimiento no menor de $3 \mathrm{~cm}$, de los extremos de las alas del perfil metálico, y una protección de $6 \mathrm{~cm}$ en sus caras. Las superficies se rematarán con llana de madera dejando una superficie rústica fina. En esta etapa el material, que se colocará, será preparado eliminando el agregado liviano mediano, sustituyéndolo por agregado liviano fino.

Por otra parte el friso de recubrimiento se hará artesanalmente en una sola capa y el revestimiento de acabado se colocaría siguiendo las instrucciones del fabricante.

Losa de piso. En relación a la losa de piso se recomienda desarrollar una ingeniería básica y de detalle para la sustitución total de la misma, dado el avanzado estado de deterioro por efecto de la corrosión severa de la armadura, debido a que el concreto de la placa está totalmente contaminado con cloruros. Para ello, en primer lugar se debe realizar el levantamiento preciso para determinar las verdaderas longitudes de vigas principales y vigas secundarias; seguido de la

V. Millano, O. Troconis de Rincón, M. Sánchez, M. Fernández, R. Fernández, W. Campos... 112 
Revista ALCONPAT, Volumen 1, Número 2, Mayo - Agosto 2011, Páginas 99 - 114

ubicación de los puntos/zonas en los cuales ocurren los derrames de agua salada que intervienen en el proceso. Adicionalmente se debe desarrollar un proyecto de drenaje de aguas saladas y aguas de lluvias, en el cual se definan las posiciones de los puntos de drenaje, los diámetros de las tuberías, su recorrido hasta los sitios de disposición final, las pendientes de la losa de piso, con sectores definidos y desniveles que garanticen el rápido escurrimiento de las aguas.

Por otra parte debe aplicarse un recubrimiento que controle la difusión de los cloruros provenientes del agua de proceso hacia la nueva placa y que al mismo tiempo permita el tráfico del personal que labora en la planta.

Así, se requiere desarrollar un proyecto estructural en detalle, para sustituir la placa existente. En relación a esto, se recomienda la sustitución por una nueva losa de concreto maciza de $20 \mathrm{~cm}$ de espesor. Es importante tomar en cuenta que la pendiente de la losa a vaciar responda a los niveles diseñados en el proyecto de drenaje con el objeto de obtener una solución integral.

Por razones de durabilidad, el concreto de la losa debe tener una relación agua/cemento máxima de 0,45 y un contenido mínimo de material cementante de $400 \mathrm{~kg} / \mathrm{m} 3$ de concreto (cemento +10 $\%$ microsílice), así como un recubrimiento de $5 \mathrm{~cm}$ sobre la armadura.

El grado de deterioro que presenta la losa de concreto sugiere que ésta debe de apuntalarse de inmediato a distancias no mayores de $1 \mathrm{~m}$ de separación entre puntales y debe permanecer así hasta la total sustitución de esta. La demolición de la losa de concreto debe realizarse una vez hayan sido reparadas las vigas del segundo nivel y las columnas del primer nivel, para que de esta manera la losa de concreto no permita la caída de escombros en los equipos de la planta baja. Una vez reparadas las vigas del primer nivel se debe proceder a la demolición de la losa por etapas. En esta fase se debe colocar una plataforma metálica en la parte inferior de la losa, que se encuentra soportada por los puntales y que sea lo suficientemente resistente para resistir el peso de los escombros, que se promueven durante la demolición de la losa. Esta plataforma tiene la finalidad de impedir la caída de escombros en los equipos de la planta baja.

La nueva Losa de concreto se vaciará por encima del nivel superior de las vigas del primer nivel, logrando así que los aceros que conforman la losa puedan pasar de manera continua a través de misma y que el vaciado de la totalidad de la losa pueda hacerse simultáneamente.

Para lograr la adherencia necesaria entre el concreto de las vigas reparadas y la nueva losa de concreto, el acabado de la cara superior de las vigas debe ser rugoso y deben de colocarse conectores de corte metálicos en la parte superior de las vigas, que queden embutidos en la losa, una vez esta sea vaciada.

El concreto suministrado en la losa debe ser premezclado y colocado mediante camiones provistos de bombas, ya que sería la única forma de poder realizar el vaciado en un mismo día, reduciendo así el tiempo de parada por este concepto.

De acuerdo al alto contenido de cemento y a la microsílice que se le debe incorporar al concreto, este se debe curar durante 28 días de manera continua, debido al alto calor de hidratación que se genera en la mezcla. Este curado debe de realizarse con agua y utilizando barreras impermeables que dificulten la salida del agua, para lo cual se puede utilizar plástico; para finalmente construir el sistema de drenaje de agua salada y de lluvias e impermeabilizar.

Evaluación y criterios de rehabilitación de la estructura de concreto reforzado de una... 
Revista ALCONPAT, Volumen 1, Número 2, Mayo - Agosto 2011, Páginas 99 - 114

\section{REFERENCIAS BIBLIOGRÁFICAS}

ASTM C-876-87 "Standard Test Method for Half-Cell Potentials of Uncoated Reinforcing Steel in Concrete". (1987). Philadelphia. USA.

O. T. de Rincón y Miembros. DURAR. Red Temática XV.B. Durabilidad de la Armadura. "Manual de Inspección, Evaluación y Diagnóstico de Corrosión en Estructuras de Hormigón Armado". CYTED ISBN 980-296-541-3. (1997). Subprograma XV. Corrosión: Impacto Ambiental sobre Materiales. Maracaibo. Venezuela.

S. Feliú, J.A. González, V. Feliú, S. Jr. Feliú, M. L. Escudero , I.Rz. Maribona, V. Austiín, C. Andrade, J.A. Bolaño.,F. Jiménez. "Corrosion Detecting Probes For Use With a Corrosion-Rate Meter for Electrochemically Determining the Corrosion Rate of Reinforced Concrete Structures". (1993). U.S. Patent No. 5.259.944.

M. Sánchez, O. T. de Rincón, S. Delgado, E. Sánchez. "Corrosion in Reinforced Concrete Exposed to Chloride-Contaminated Waters". Materials Performance, Vol. 46 No. 3, NACE International. (2007). pp. 48-53.

DURACON Collaboration, O. Trocónis de Rincón and coauthors. "Durability of concrete structures: Duracon, an Iberoamerican Project. Preliminary results”. Building \& Environment. Elsevier Science LTD Publication. Vol 41 (7). (2006). pp. 952-962.

DURACON Collaboration, O. Trocónis de Rincón and coauthors. "Effect of the Marine Environment on Reinforced Concrete Durability in Iberoamerican Countries: DURACON Project/CYTED”. Corrosion Science. Elsevier Science LTD Publication. Vol. 49 (7). (2007). pp. 2832-2843.

International Concrete Repair Institute (ICRI). "Guide for Surface Preparation for the Repair of Deteriorated Concrete Resulting from Reinforcing Steel Corrosion”. (1995). Guideline Number 03730 